\title{
Inhibitory effect of metformin combined with gemcitabine on pancreatic cancer cells in vitro and in vivo
}

\author{
YUQI SHI", ZHILONG HE*, ZHENYU JIA and CHUNFANG XU \\ Department of Gastroenterology, The First Affiliated Hospital of Soochow University, Suzhou, Jiangsu 215006, P.R. China
}

Received September 3, 2015; Accepted June 2, 2016

DOI: $10.3892 / \mathrm{mmr} .2016 .5592$

\begin{abstract}
Pancreatic cancer is a malignant digestive system tumor with a particularly poor prognosis, and is the fourth leading cause of cancer-associated mortality in the USA. The anti-diabetic therapeutic agent, metformin (MET) has been demonstrated to exert anti-tumor effects. The present study assessed the ability of MET, alone or in combination with gemcitabine (GEM), to inhibit the growth of the human CFPAC-1 pancreatic cancer cell line in vitro and in vivo. Cell counting kit- 8 assays were performed to measure CFPAC-1 cell viability and apoptosis was detected with annexin V/propidium iodide. Cell cycle analysis was conducted by flow cytometry. The mRNA and protein levels of B-cell lymphoma-extra large (Bcl-xL), Bcl2 associated X protein (Bax), caspase-3, survivin and cyclin D1 in CFPAC-1 cells and tumor tissues were detected by reverse transcription-polymerase chain reaction and western blotting, respectively. Furthermore, the expression levels of caspase-3 and proliferating cell nuclear antigen in tumor tissues were detected by immunohistochemistry. The results demonstrated that following MET treatment, the grow th of CFPAC-1 cells and xenografts in nude mice was inhibited, the expression levels of Bcl-xL, survivin and cyclin D1 were downregulated, while the expression levels of Bax and caspase-3 were upregulated. These effects were enhanced when MET was administered in combination with GEM. The mechanism underlying the anti-tumor effect of MET may be associated with the induction of cell apoptosis and the inhibition of proliferation.
\end{abstract}

Correspondence to: $\mathrm{Dr}$ Chunfang $\mathrm{Xu}$, Department of Gastroenterology, The First Affiliated Hospital of Soochow University, 188 Shizi Street, Gusu, Suzhou, Jiangsu 215006, P.R. China

E-mail: xcf601@163.com

${ }^{*}$ Contributed equally

Key words: metformin, pancreatic cancer, apoptosis, proliferation, gemcitabine

\section{Introduction}

Pancreatic cancer is the fourth leading cause of cancer-associated mortality for men and women in the USA, with a 5-year survival rate of $<5 \%$ (1). To date, the sole potential cure for pancreatic cancer is surgery (2). However, $\sim 80 \%$ patients present when the cancer is too advanced for surgery (3). For patients with locally advanced or metastatic inoperative pancreatic cancer, chemotherapy and radiotherapy are the standard treatments. Gemcitabine (GEM) is currently the first-line therapeutic agent prescribed for advanced pancreatic cancer; however, its efficacy is limited, with a median survival extension of just six weeks (4). Therefore, adjuvant strategies have been increasingly investigated to improve these outcomes.

Metformin (MET) is widely used in the treatment of type 2 diabetes mellitus and has been investigated due to its anti-tumor effects (5). Previous studies have suggested that MET has an effect on various cancer types (6), including pancreatic cancer. Certain in vitro and in vivo studies using mouse xenograft models have indicated that MET may exert direct anti-tumor activity via the inhibition of cancer cell proliferation, migration and invasion, promotion of cancer cell apoptosis, and suppression of tumor growth (7-9). However, the underlying mechanism of these effects and the combination of MET with conventional chemotherapy remains to be clarified.

The aim of the present study was to investigate the underlying anti-tumor mechanism of MET on the growth of the CFPAC-1 human pancreatic cell line, and to evaluate the effects of combination therapy with MET and GEM in vitro and in vivo.

\section{Materials and methods}

Cell lines and animals. The human CFPAC-1 pancreatic ductal adenocarcinoma cell line was donated by the Institute of Hematology of Soochow University (Suzhou, China). The cells were incubated in $75-\mathrm{cm}^{2}$ cell culture flasks and maintained in RPMI-1640 (Gibco; Thermo Fisher Scientific, Inc., Waltham, MA, USA), supplemented with $10 \%$ fetal bovine serum (Gibco; Thermo Fisher Scientific, Inc.), $100 \mathrm{U} / \mathrm{ml}$ penicillin and $100 \mu \mathrm{g} / \mathrm{ml}$ streptomycin in a humidified atmosphere composed of $5 \% \mathrm{CO}_{2}$ at $37^{\circ} \mathrm{C}$. A total of 20 specific-pathogen-free female athymic BALB/c nu/nu mice (age, 4-5 weeks; weight, 15-16 g) were purchased from the Shanghai Laboratory Animal Center (Shanghai, China). Mice were allowed free access to 
sterilized water and food, and were housed in individual ventilated cages at $23 \pm 5^{\circ} \mathrm{C}$ under a 12 -h light/dark cycle. The experimental protocol was approved by the Animal Care and Use Committee of Soochow University.

Cell counting kit (CCK)-8 assay. The CFPAC-1 cells were trypsinized with $0.05 \%$ trypsin and then plated in 96 -well plates with $100 \mu \mathrm{l}$ medium per well. Following an overnight incubation in $5 \% \mathrm{CO}_{2}$ at $37^{\circ} \mathrm{C}$, cells were treated with normal saline (NS) or MET $(0,1,2.5,5,10,20,40$ or $60 \mathrm{mmol} / \mathrm{l}$; Sigma-Aldrich, St. Louis, MO, USA), with six replicates per concentration. Following incubations of 24,48 or $72 \mathrm{~h}$ at $37^{\circ} \mathrm{C}$, cells were incubated for $1-4 \mathrm{~h}$ with $10 \mu \mathrm{l}$ CCK- 8 reagent per well. Cell viability was measured with CCK- 8 according to the manufacturer's instructions (Peptide Institute, Inc., Osaka, Japan), and the survival and growth inhibition rates were calculated as follows: Survival rate $=$ absorbance of $\operatorname{MET}(1,2.5,5,10,20,40$ or $60 \mathrm{mmol} / \mathrm{l}) /$ absorbance of MET $(0 \mathrm{mmol} / \mathrm{l}) \times 100$; inhibition rate $=[$ absorbance of MET $(0 \mathrm{mmol} / \mathrm{l})$ - absorbance of MET $(1,2.5,5,10,20,40$ or $60 \mathrm{mmol} / \mathrm{l})]$ / absorbance of MET $(0 \mathrm{mmol} / \mathrm{l}) \times 100$. In the combination therapy experiment, cells were treated with MET $(20 \mathrm{mmol} / \mathrm{l})$ and GEM $(5 \mu \mathrm{mol} / \mathrm{l})$ alone or in combination and cell viability was measured as above.

Cell cycle analysis and annexin V/propidium iodide (PI) assay. The CFPAC-1 cells were placed in 6-well plates at $5 \times 10^{4}$ cells/well and treated with NS or MET $(10,20$ or $40 \mathrm{mmol} / \mathrm{l})$. Separate cell cultures were collected and trypsinized $48 \mathrm{~h}$ later, then washed twice with cold phosphate-buffered saline (PBS). The cells were subsequently incubated with an annexin V/PI double staining solution (Sigma-Aldrich) at room temperature. Fifteen min later, the stained cells were analyzed by flow cytometry and the percentage of apoptotic cells (those in the lower right quadrant) was calculated with ModFit LT software version 4.0 (Verity Software House, Inc., Topsham, ME, USA). Cell cycle analysis was performed by flow cytometry using CellQuest Pro software version 5.1 (BD Biosciences, Franklin Lakes, NJ, USA). In combination therapy experiments, cells were treated with MET $(20 \mathrm{mmol} / \mathrm{l})$ and GEM $(5 \mu \mathrm{mol} / \mathrm{l})$, alone or in combination for $48 \mathrm{~h}$. The percentage of apoptotic cells was calculated as above.

Mice xenograft model. The CFPAC-1 cells were resuspended in serum-free RPMI-1640 at a concentration of $1 \times 10^{7}$ cells $/ \mathrm{ml}$. A total volume of $0.2 \mathrm{ml}$ cell suspension $\left(2 \times 10^{6}\right.$ cells $)$ was then injected subcutaneously into the right anterior armpit of nude mice, to establish a xenograft model. The 20 injected mice were randomly divided into four groups: NS-treated control, MET-treated, GEM-treated and combination therapy ( $\mathrm{n}=5$ per group). MET $(200 \mathrm{mg} / \mathrm{kg}$, daily), GEM $(50 \mathrm{mg} / \mathrm{kg}$, twice/week) or combination therapy [MET $(200 \mathrm{mg} / \mathrm{kg}$, daily)+GEM $(50 \mathrm{mg} / \mathrm{kg}$, twice/week)] were administered intraperitoneally for four weeks. The tumor volume was measured with calipers every second day and calculated as follows: Volume $\left(\mathrm{mm}^{3}\right)=4 \pi / 3 x(\text { width / 2) })^{2}$ (length / 2). The mice were weighed weekly then sacrificed by cervical dislocation following four weeks of treatment and the tumors were collected.
Reverse transcription-polymerase chain reaction (RT-PCR) assay. Total RNA was extracted from CFPAC-1 cells and tumor tissues using TRIzol ${ }^{\circledR}$ reagent (Invitrogen; Thermo Fisher Scientific, Inc.). The first strand cDNA was synthesized with the Omniscript RT kit (Qiagen GmbH, Hilden, Germany), using 2,000 ng RNA per $20 \mu \mathrm{l}$ reaction and an oligo (dT) primer. PCR reactions were performed for 35 cycles. Each cycle was performed as follows: Denaturation for $30 \mathrm{sec}$ at $94^{\circ} \mathrm{C}$, annealing for $30 \mathrm{sec}$ at $60^{\circ} \mathrm{C}$ and polymerization for $30 \mathrm{sec}$ at $72^{\circ} \mathrm{C}$. Primers used in the PCR reaction were as follows: Forward, 5'-CGGGCATTCAGTGACCTGAC-3' and reverse, 5'-TCAGGAACCAGCGGTTGAAG-3' for B-cell lymphoma-extra large (Bcl-xL); forward, 5'-GCGTCCACC AAGAAGCTGA-3' and reverse, 5'-ACCACCCTGGTCTTG GATCC-3' for Bcl2 associated X protein (Bax); forward, 5'-GTCTCAATGCCACAGTCCAGT-3' and reverse, 5'-AGC AAACCTCAGGGAAACATT-3 for caspase-3; forward, 5'-TACGCCTGTAATACCAGCAC-3' and reverse, 5'-TCT CCGCAGTTTCCTCAA-3' for survivin; forward, 5'-TGT TCGTGGCCTCTAAGATG-3' and reverse, 5'-ACTCCAGAA GGGCTTCAATC-3' for cyclin D1; and forward, 5'-AGCGGG AAATCGTGCGTG-3' and reverse, 5'-CAGGGTACATGG TGGTGCC-3' for $\beta$-actin. The PCR products were detected using Molecular Analyst software version 2.10e (BioRad Laboratories, Inc., Hercules, CA, USA). $\beta$-actin served as an internal standard.

Western blot assay. Cells or tumor tissue were lyzed with radioimmunoprecipitation assay buffer on ice for $30 \mathrm{~min}$ and centrifuged at $12,000 \mathrm{x} \mathrm{g}, 4^{\circ} \mathrm{C}$ for $10 \mathrm{~min}$. The protein samples $(20 \mu \mathrm{g})$ were separated on a $10 \%$ SDS-PAGE gel, at $80 \mathrm{~V}$ (stacking gel) and $100 \mathrm{~V}$ (separating gel), and transferred onto nitrocellulose membranes. The membranes were blocked with PBS-Tween (PBS-T) containing 5\% skimmed milk powder for $1 \mathrm{~h}$ at room temperature. The membranes were then incubated at $4^{\circ} \mathrm{C}$ overnight with primary mouse monoclonal antibodies, diluted 1:1,000, against Bcl-xL (catalog no. sc-8392), Bax (catalog no. sc-7480), caspase-3 (catalog no. sc-65497), survivin (catalog no. sc-374616) and cyclin D1 (catalog no. sc-8396), purchased from Santa Cruz Biotechnology, Inc. (Dallas, TX, USA). Subsequently, the membranes were washed with PBS-T three times and incubated for $1 \mathrm{~h}$ with a goat anti-mouse IgG antibody conjugated to horseradish peroxidase (HRP) (1:1,000; catalog no. sc-2031; Santa Cruz Biotechnology, Inc.). Membranes were then washed three times with PBS-T, and protein bands were visualized using an enhanced chemiluminescence (ECL) -detection system (Beyotime Institute of Biotechnology, Haimen, China).

Immunohistochemistry. Tumor xenografts were fixed in formalin and embedded in paraffin blocks, which were sliced into 4- $\mu \mathrm{m}$ thick sections for immunohistochemical staining.

Following deparaffinization, the sections were incubated at $4{ }^{\circ} \mathrm{C}$ overnight with primary mouse monoclonal antibodies, diluted 1:200, against caspase-3 (catalog no. 65497) or proliferating cell nuclear antigen (PCNA; catalog no. sc-25280), purchased from Santa Cruz Biotechnology, Inc. The sections were washed three times with PBS-T, and incubated for $1 \mathrm{~h}$ at room temperature with a goat anti-mouse $\operatorname{IgG}$ antibody conjugated to HRP (1:200; catalog no. sc-2031; Santa Cruz 
Biotechnology, Inc.). The slices were washed with PBS-T three times, and incubated in diaminobenzidine (Sangon Biotech Co., Ltd., Shanghai, China) and counterstained with hematoxylin (Sangon Biotech Co., Ltd.) for $1 \mathrm{~min}$. Images were captured using a light microscope (magnification, $\mathrm{x} 400$; model CKX41-A32RC; Olympus Corporation, Tokyo, Japan).

Statistical analysis. Data were expressed as the mean \pm standard error and analyzed using SPSS version 18.0 (SPSS, Inc., Chicago, IL, USA). Statistical analysis was performed using one-way analysis of variance. The Student-Newman-Keuls (SNK) method was used as a post-hoc test. The Kruskal-Wallis test was used to evaluate the differences of categorical values, followed by the Mann-Whitney U test as a post-hoc test. $\mathrm{P}<0.05$ was considered to indicate a statistically significant difference.

\section{Results}

Effect of MET on growth of CFPAC-1 cells. The human CFPAC-1 pancreatic ductal adenocarcinoma cells were treated with various concentrations of MET for 24, 48 or $72 \mathrm{~h}$, and survival and growth inhibition rates were evaluated with the CCK-8 assay. The proliferation and survival of CFPAC-1 cells was inhibited in a dose-and time-dependent manner (Fig. 1A and B). Cell apoptosis was determined by annexin $\mathrm{V} / \mathrm{PI}$ assay. The percentage of apoptotic cells increased in a dose-dependent manner following a $48 \mathrm{~h}$ incubation with MET (Fig. 1C; Table I). Cell cycle analysis revealed that cells in the $G_{0} / G_{1}$ phase increased significantly following MET treatment in a dose-dependent manner (Fig. 1D and E; Table II). Furthermore, RT-PCR and western blot analysis demonstrated that the expression levels of Bcl-xL, survivin and cyclin D1 were reduced following $48 \mathrm{~h}$ of MET treatment (Fig. 1F and G). By contrast, the expression levels of Bax and caspase-3 increased following MET treatment.

Effect of MET combined with GEM on growth of CFPAC-1 cells. The CFPAC-1 cells were treated with MET, GEM or a combination of the two agents. CCK- 8 assay revealed that the proliferation and survival of CFPAC-1 cells were inhibited significantly following treatment with MET in combination with GEM, compared with MET or GEM alone (combined treatment vs. MET treatment at 24, 48 and $72 \mathrm{~h}, \mathrm{P}<0.001$; combined treatment vs. GEM treatment at 24, 48 and $72 \mathrm{~h}$, $\mathrm{P}<0.001$; Fig. 2A and B). In addition, the percentage of apoptotic cells increased following combination therapy compared with MET or GEM treatment alone (Fig. 2C; Table III). The mRNA and protein expression levels of Bcl-xL, survivin and cyclin D1 were decreased in MET and GEM alone treatment groups, and a greater decrease was observed in the combination therapy group (Fig. 2D and E). Similarly, a greater increase in Bax and caspase-3 expression levels was observed in the combination therapy group compared with the single treatment groups.

Growth inhibitory effect of MET in vivo. All mice survived for the duration of the experiment with no observable toxic effect, such as weight loss. Mice were sacrificed at 28 days and the weights of the xenografts were measured. In comparison to the NS-treated control group, xenografts from mice treated with
Table I. Impact of MET on viability of CFPAC-1 cells in vitro.

MET concentration ( $\mathrm{mmol} / \mathrm{l})$

\begin{tabular}{lllll}
\cline { 2 - 4 } Parameter & 0 & 10 & 20 & 40 \\
\hline
\end{tabular}

Apoptosis, \% $3.01 \pm 0.4913 .77 \pm 1.31^{\mathrm{a}} 22.63 \pm 1.45^{\mathrm{a}} \quad 32.97 \pm 3.19^{\mathrm{a}}$

As measured by an annexin V/propidium iodide assay. Data are expressed as the mean \pm standard error. ${ }^{\text {aP }}<0.05$ vs. normal saline treated control cells. MET, metformin.

MET, GEM or combination therapy were smaller in size and weight (MET vs. normal saline treatment, $\mathrm{P}=0.007$; GEM vs. normal saline treatment, $\mathrm{P}=0.001$; combined vs. normal saline treatment, $\mathrm{P}<0.001$; Fig. 3A-C). Furthermore, the tumor volume and weight were decreased significantly following combined treatment (combined vs. MET treatment, $\mathrm{P}<0.001$; combined vs. GEM treatment, $\mathrm{P}=0.001)$. Bcl-xL, survivin, Bax, caspase-3 and cyclin D1 mRNA and protein expression levels followed a similar pattern to that of the in vitro experiment (Fig. 3D and $\mathrm{E}$ ). The protein expression level of caspase-3 was markedly upregulated in the combination therapy group, and this was confirmed by immunohistochemistry (Fig. 4A). However, expression of PCNA protein was decreased following treatment (Fig. 4B).

\section{Discussion}

The glucose-lowering effect of MET is associated with an increase in insulin sensitivity in vivo, resulting in increased glucose uptake, decreased gluconeogenesis and reduced plasma glucose concentrations. Emerging evidence from in vitro, in vivo and epidemiological studies suggests an anti-tumor role of MET (10-12). The underlying mechanisms are complex and require further investigation. It has been demonstrated that MET activates the 5' adenosine monophosphate-activated protein kinase/mammalian target of rapamycin signaling pathway through inhibition of complex 1 of the mitochondrial respiratory chain $(13,14)$. In addition, MET has indirect anti-tumor effects via the reduction of circulating insulin and insulin growth factor 1 levels (15). In vitro, MET induces cell cycle arrest, thus inhibiting proliferation and inducing cell apoptosis. Furthermore, MET affects the proliferation of cancer stem cells, reduces DNA damage and inhibits the inflammatory response (16-18).

In the present study, the influence of MET on the apoptosis and proliferation of the human CFPAC-1 pancreatic ductal adenocarcinoma cell line was investigated in vitro and in vivo. The mechanism underlying induction of apoptosis in cancer cells by MET may be associated with altered expression of pro-apoptotic and anti-apoptotic molecules. In addition, MET arrested cells in the $\mathrm{G}_{0} / \mathrm{G}_{1}$ phase and downregulated the expression of cyclin D1 and PCNA, demonstrating anti-proliferative activity. Furthermore, the pro-apoptotic and anti-proliferative activities of MET were enhanced when it was administered in combination with GEM.

Appropriate apoptotic signaling is crucial for preserving tissue homeostasis by maintaining a healthy balance between 

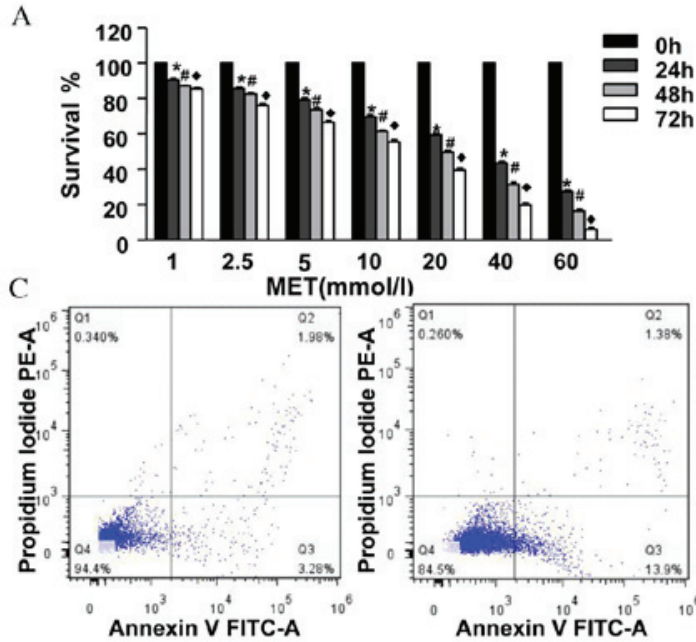

Control

D

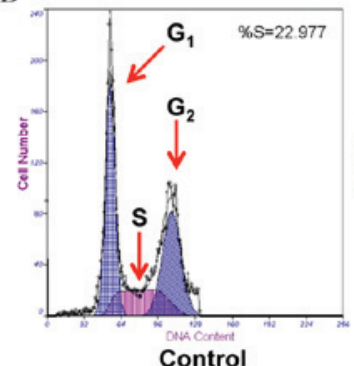

Control

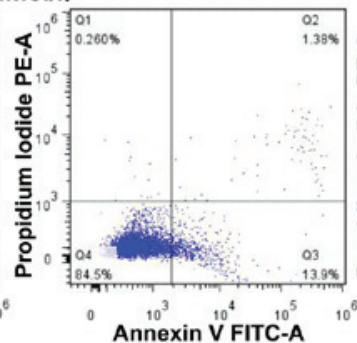

MET(10mmol/l)

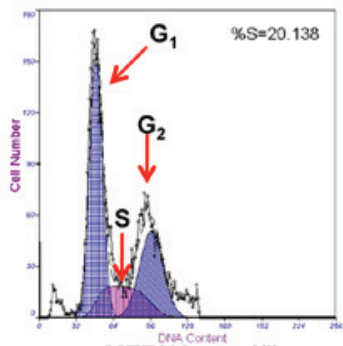

$\operatorname{MET}(10 \mathrm{mmol} / \mathrm{I})$

B
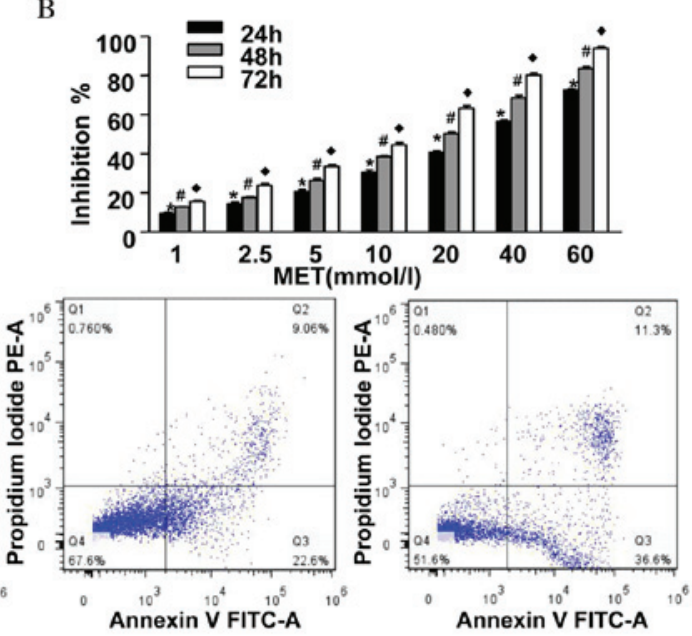

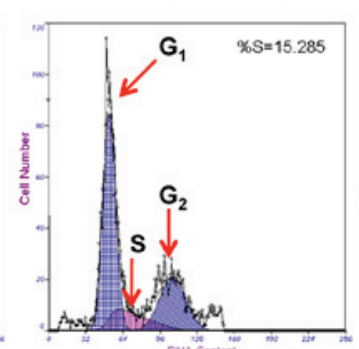

MET(20mmol/l)
MET(40mmol/l)

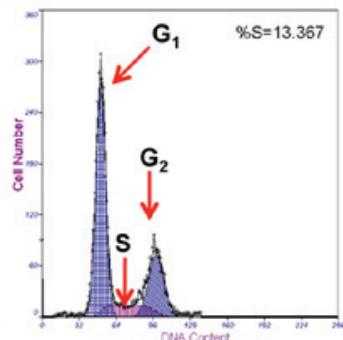

$\operatorname{MET}(40 \mathrm{mmol} / \mathrm{l})$
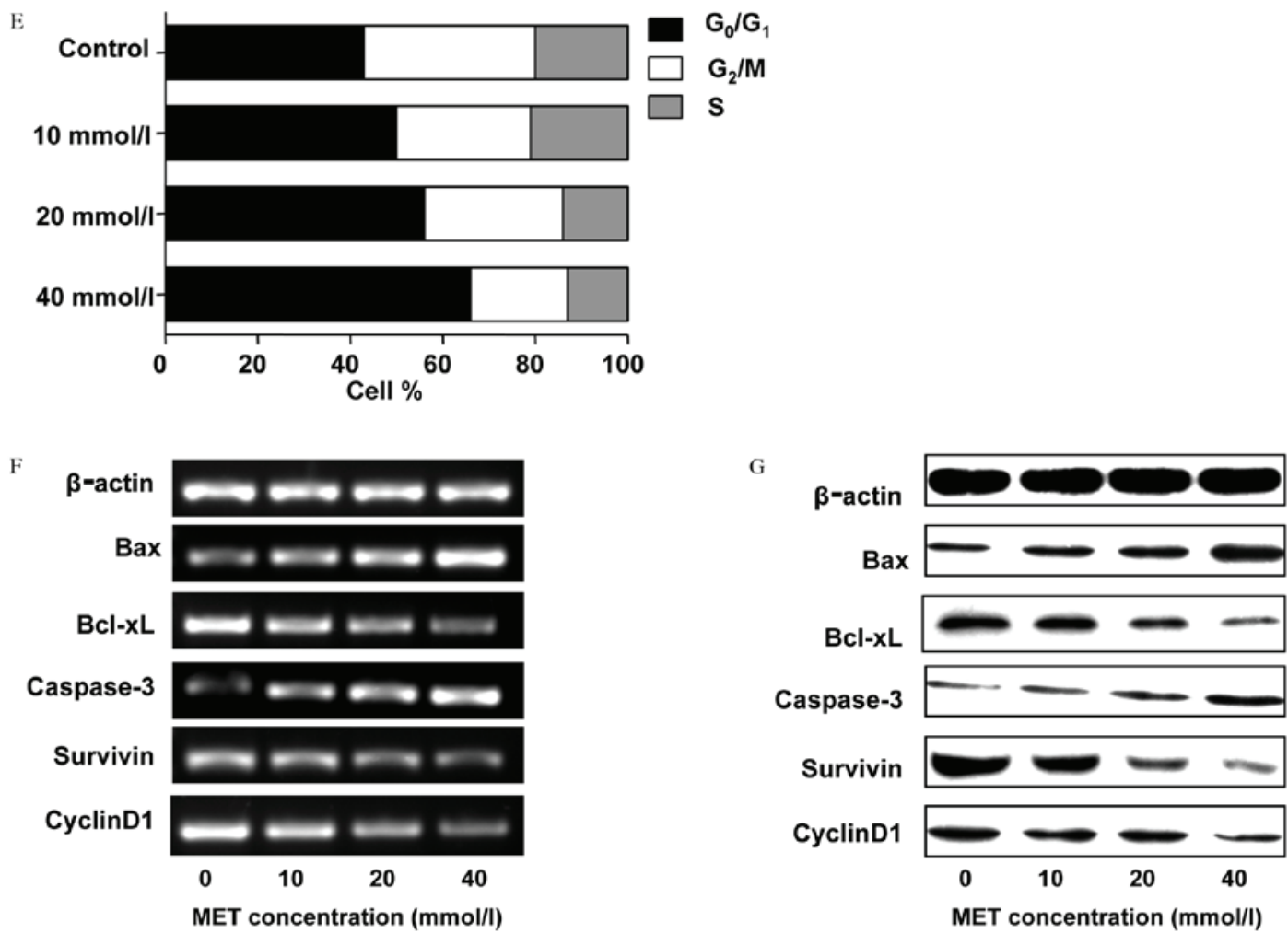

Figure 1. Inhibitory effect of MET on the growth of the human CFPAC-1 pancreatic cancer cell line in vitro. CFPAC-1 cells were incubated with various concentrations of MET, from $0-60 \mathrm{mmol} / 1$, for $0,24,48$ or $72 \mathrm{~h}$. The cell counting kit-8 assay was then conducted to analyze (A) cell viability and (B) growth inhibition rates. MET treatment decreased survival and inhibited growth of CFPAC-1 cells. Data are presented as the mean \pm standard error. (C) The percentage of apoptotic CFPAC-1 cells (the lower right quadrant, annexin $\mathrm{V}^{+} \mathrm{PI}^{-}$) was analyzed using an annexin $\mathrm{V} /$ propidium iodide assay. (D) Cell cycle analysis was conducted by flow cytometry. (E) Percentage of cells in $\mathrm{G}_{0} / \mathrm{G}_{1}$ phases increased following MET treatment. Subsequent to treatment with MET, CFPAC-1 cells were harvested and the (F) mRNA and (G) protein expression levels of Bax, Bcl-xL, caspase-3, survivin and cyclin D1 were analyzed by reverse transcription-polymerase chain reaction and western blotting, respectively. $\beta$-actin served as an internal standard. The expression levels of Bax and caspase-3 increased following MET treatment, while Bcl-xL, survivin and cyclin D1 were reduced. ${ }^{*} \mathrm{P}<0.05$ vs. $0 \mathrm{~h}$; ${ }^{\#} \mathrm{P}<0.05$ vs. $24 \mathrm{~h}$; ${ }^{~} \mathrm{P}<0.05$ vs. $48 \mathrm{~h}$. MET, metformin; Bcl-xL, B-cell lymphoma-extra large; Bax, Bcl2 associated X protein. 
Table II. Impact of MET on cell cycle of CFPAC-1 cells in vitro.

MET concentration ( $\mathrm{mmol} / \mathrm{l})$

Cell cycle phase

0

20

40

\begin{tabular}{lllll}
\hline $\mathrm{G}_{0} / \mathrm{G}_{1}, \%$ & $42.89 \pm 1.02$ & $49.59 \pm 3.15^{\mathrm{a}}$ & $56.03 \pm 1.49^{\mathrm{a}}$ & $65.93 \pm 0.27^{\mathrm{a}}$ \\
$\mathrm{G}_{2} / \mathrm{M}, \%$ & $38.28 \pm 4.93$ & $28.72 \pm 1.32^{\mathrm{a}}$ & $30.70 \pm 2.75^{\mathrm{a}}$ & $22.01 \pm 2.95^{\mathrm{a}}$ \\
$\mathrm{S}, \%$ & $20.12 \pm 3.38$ & $21.68 \pm 4.18$ & $13.27 \pm 1.78^{\mathrm{a}}$ & $13.58 \pm 0.43^{\mathrm{a}}$ \\
\hline
\end{tabular}

Data are expressed as the mean \pm standard error. ${ }^{\text {a }}<<0.05$ vs. normal saline treated control cells. MET, meformin.

Table III. Impact of MET combined with GEM on the viability of CFPAC-1 cells in vitro.

\begin{tabular}{|c|c|c|c|c|}
\hline \multirow[b]{2}{*}{ Parameter } & \multicolumn{4}{|c|}{ Treatment group } \\
\hline & Control & $20 \mathrm{mmol} / 1 \mathrm{MET}$ & $5 \mu \mathrm{mol} / 1 \mathrm{GEM}$ & $20 \mathrm{mmol} / 1 \mathrm{MET}+5 \mu \mathrm{mol} / 1 \mathrm{GEM}$ \\
\hline Apoptosis, $\%$ & $3.01 \pm 0.49$ & $24.53 \pm 2.18^{\mathrm{a}}$ & $22.37 \pm 1.61^{\mathrm{a}}$ & $52.07 \pm 2.81^{\mathrm{a}, \mathrm{b}}$ \\
\hline
\end{tabular}

As measured by an annexin V/propidium iodide assay. Data are expressed as the mean \pm standard error. ${ }^{\text {a }}<0.05$ vs. normal saline treated control cells; ${ }^{\text {P }}<0.05$ vs. MET- and GEM-treatment MET, metformin; GEM, gemcitabine.

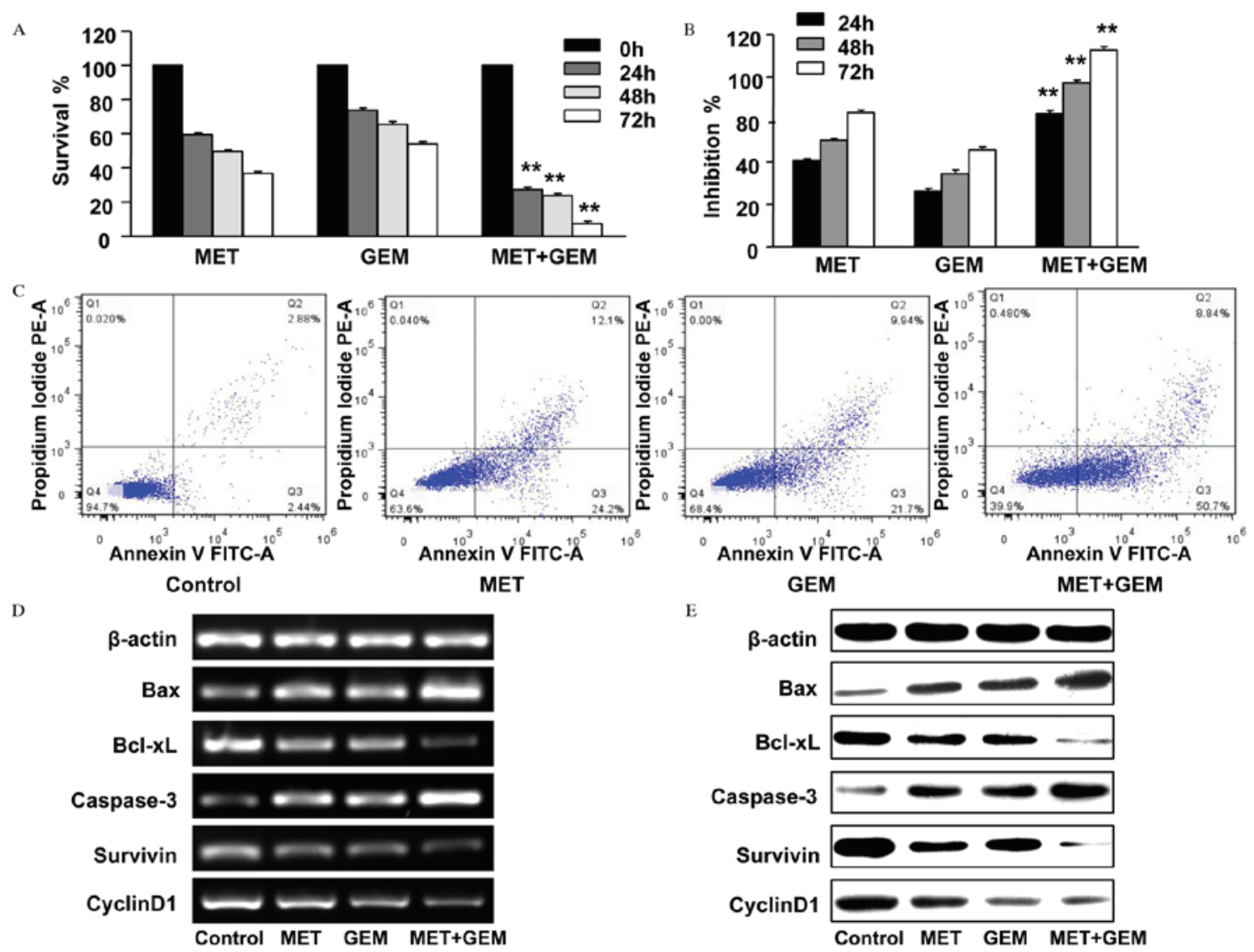

Figure 2. Inhibitory effect of MET combined with GEM on the growth of the human CFPAC-1 pancreatic cancer cell line in vitro. CFPAC-1 cells were incubated with $20 \mathrm{mmol} / 1 \mathrm{MET}, 5 \mu \mathrm{mol} / 1 \mathrm{GEM}$ or MET and GEM in combination for $0,24,48$ or $72 \mathrm{~h}$. The cell counting kit- 8 assay was conducted to analyze (A) cell viability and (B) growth inhibition rates. Combination therapy significantly increased the effectiveness of MET and GEM. The data are presented as the mean \pm standard error. (C) The percentage of apoptotic CFPAC-1 cells (the lower right quadrant, annexin $\mathrm{V}^{+} \mathrm{PI}^{-}$) was analyzed using an annexin V/propidium iodide assay. Subsequent to treatment with $20 \mathrm{mmol} / 1 \mathrm{MET}, 5 \mu \mathrm{mol} / 1 \mathrm{GEM}$ or MET and GEM combined, CFPAC-1 cells were harvested and the (D) mRNA and (E) protein expression levels of Bax, Bcl-xL, caspase-3, survivin and cyclin D1 were analyzed by reverse transcription-polymerase chain reaction and western blotting, respectively. ${ }^{* *} \mathrm{P}<0.05$ vs. MET or GEM treatment alone. MET, metformin; GEM, gemcitabine; Bcl-xL, B-cell lymphoma-extra large; Bax, Bcl2 associated X protein. 


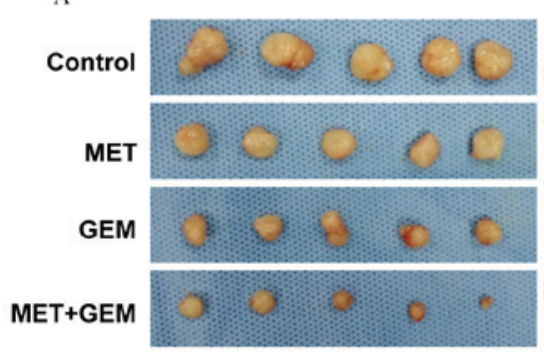

B

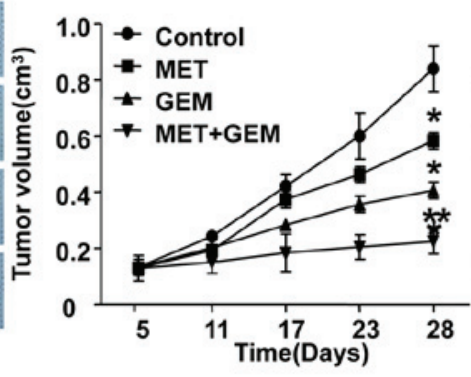

C

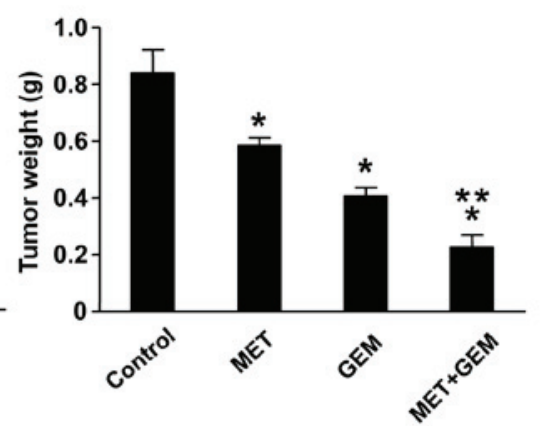

D

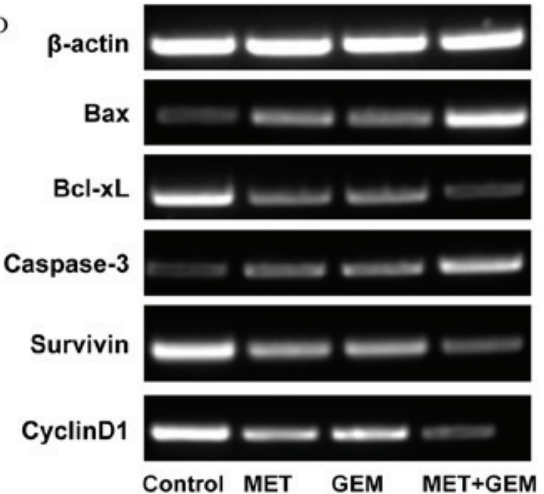

E

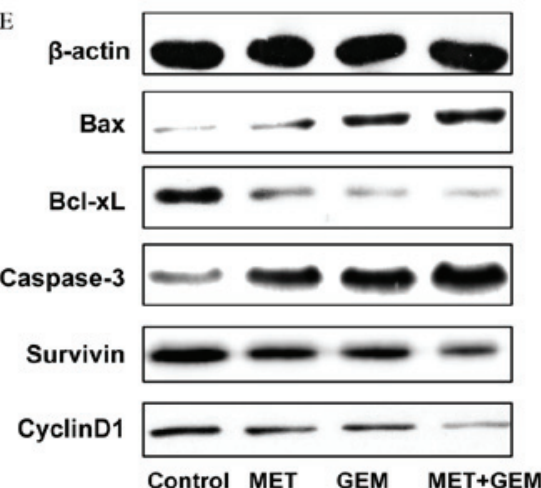

Figure 3. Inhibitory effect of combined treatment with MET and GEM on the growth of the human CFPAC-1 pancreatic cancer cell line in vivo. CFPAC-1 cells were injected into nude mice, which were then treated for 28 days with $200 \mathrm{mg} / \mathrm{kg} \mathrm{MET}, 50 \mathrm{mg} / \mathrm{kg} \mathrm{GEM}$ or MET and GEM in combination. (A) Gross morphology of tumors at sacrifice. (B) Volume changes in the xenografts. Treatment with MET, GEM or a combination of the two significantly inhibited tumor growth, compared with the control group. The data are presented as the mean \pm SE. (C) Following 28 days of treatment, the tumor weights were significantly decreased in all three treatment groups compared with the control group. The data are presented as the mean \pm SE. (D) mRNA and (E) protein expression levels of Bax, Bcl-xL, caspase-3, survivin and cyclin D1 in nude mice xenografts were analyzed by reverse transcription-polymerase chain reaction and western blotting, respectively. 'P<0.05 vs. normal saline-treated control group; ${ }^{* *} \mathrm{P}<0.05$ vs. MET or GEM treatment alone. MET, metformin; GEM, gemcitabine; Bcl-xL, B-cell lymphoma-extra large; Bax, Bcl2 associated X protein; SE, standard error.

cell death and cell survival. The ratio of pro- and anti-apoptotic molecules regulates cell death. Carcinogenesis may occur if the balance is disturbed and apoptosis in malignant cells is reduced. Bcl-xL and Bax are members of the Bcl-2 protein family and, as such, are important in apoptosis. Bax mediates the permeabilization of the outer mitochondrial membrane and the release of cytochrome $c$ into the cytoplasm, which activates caspase-3 to induce chromosome cleavage and apoptosis (19). However, the effect triggered by $\mathrm{Bax}$ is blocked by $\mathrm{Bcl}-\mathrm{xL}$ (20). It has been reported that $>50 \%$ of cancers are associated with excessive expression of Bcl-xL (21). Survivin belongs to the inhibitor of apoptosis proteins (IAPs) family and is considered a node protein, inhibiting apoptosis and regulating cell mitosis (22). Promising cancer treatment strategies that target apoptotic inhibitors, including Bcl-2 family proteins and IAPs are currently under investigation (23).

The cell cycle is divided into three phases: $G_{0}$, the interphase $\left(G_{1}, S\right.$ and $\left.G_{2}\right)$ and $M$. Cells are quiescent in the $G_{0}$ phase. The $\mathrm{G}_{1}$ checkpoint control mechanism ensures that the cell is prepared for DNA synthesis. Cyclin D1 is an important cell cycle regulatory protein, which performs a positive role during the crucial restriction point of the $G_{1} / S$ transition. Cyclin D1 expression and accumulation are induced by growth factors and occur at multiple levels, including increased transcription, translation and protein stability (24).
PCNA is a DNA clamp that acts as a processivity factor for DNA polymerase $\delta$ in eukaryotic cells, and the presence of PCNA is a specific marker of cell proliferation (25).

Pancreatic cancer remains one of the most fatal types of cancer despite the oncological advances achieved over the past two decades. Patients suffering from pancreatic cancer have a median survival time of 4-6 months (26). GEM, the first-line chemotherapeutic agent prescribed in unresectable cases, only marginally improves the outcome. GEM-based combination therapies, including cisplatin, capecitabine and exatecan have failed to make any significant improvements (27-29). Furthermore, combination therapies may be more toxic and, therefore, less well tolerated (27-29). The lack of effective and less toxic treatment options for pancreatic cancer has prompted investigations into novel combined treatment strategies.

There are complex associations between diabetes mellitus and pancreatic cancer, as diabetes may be a risk factor for, or a result of, pancreatic cancer (30). Previous studies have demonstrated that MET is beneficial for pancreatic cancer prognosis $(31,32)$. A borderline significant relative survival benefit was observed in MET-treated patients compared with non-MET-treated patients [hazard ratio (HR), 0.80; 95\% confidence interval (CI), 0.62-1.03] in a pooled analysis of four publications containing 1,429 patients (33). However, few clinical trials of MET in pancreatic cancer treatment have been reported. 
A

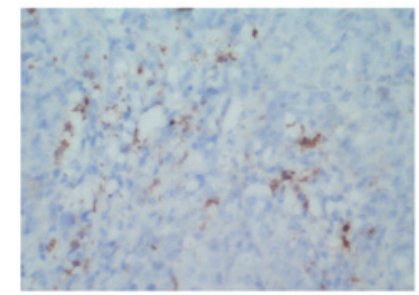

Control

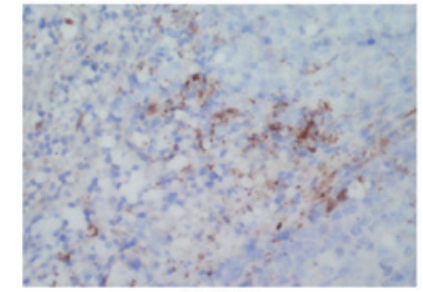

GEM

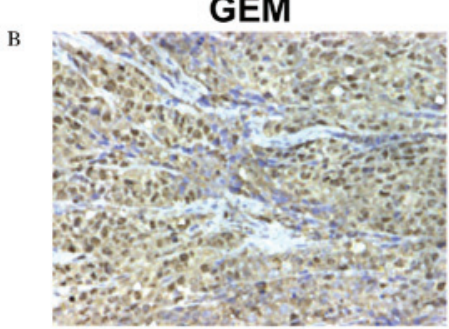

Control

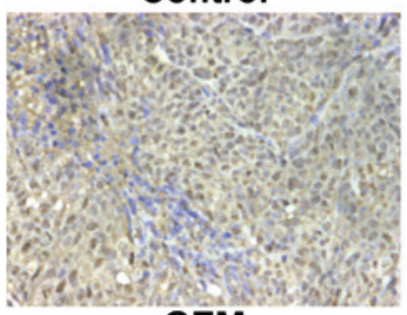

GEM

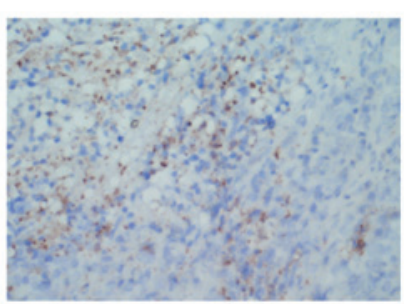

MET

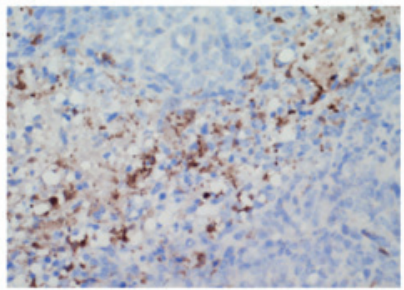

MET+GEM

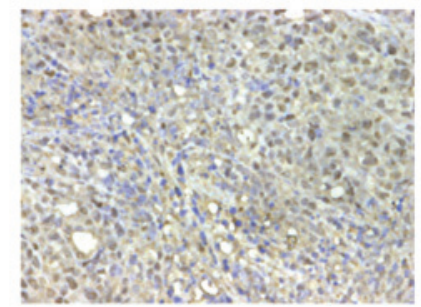

MET

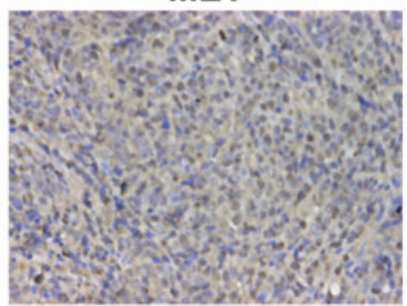

MET+GEM

Figure 4. Effect of combination therapy with $200 \mathrm{mg} / \mathrm{kg}$ MET and $50 \mathrm{mg} / \mathrm{kg}$ GEM in the nude mouse xenograft model. Immunohistochemical detection of (A) caspase-3 and (B) PCNA. Staining of caspase-3 increased following combination therapy, while PCNA staining decreased. Magnification, $\mathrm{x} 400$. MET, metformin; GEM, gemcitabine; PCNA, proliferating cell nuclear antigen.

Between 2010 and 2014, Kordes et al (34) presented a randomized, placebo-controlled trial of MET in the treatment of patients with advanced pancreatic cancer. Despite the laboratory evidence of anti-tumor activity, MET addition did not improve the clinical outcome for these patients (median survival of 7.6 months in the placebo group vs. 6.8 months in the MET group; HR, 1.056; 95\% CI, 0.72-1.55). The authors hypothesized that the conventional anti-diabetic dose of MET may fail to accumulate to a sufficient concentration to cause energetic stress (34). Blood MET concentrations were in the micromolar range, significantly lower than that of in vitro studies, which demonstrated the direct anti-tumor effects of MET. In addition, only patients with advanced pancreatic cancer were included in the trial (34). Future studies focusing on patients with hyperinsulinaemia or patients with tumors expressing markers of sensitivity to energetic stress are required.

In conclusion, MET inhibited the growth of pancreatic cancer cells via the induction of apoptosis and the reduction of proliferation. In addition, the efficacy of MET was significantly improved when administered in combination with GEM.
The findings of the present study may provide an alternative strategy for the treatment of pancreatic cancer, but requires validation in clinical trials. In addition, the mechanisms underlying the effects of apoptosis induction and proliferation reduction require additional investigation. Furthermore, future studies are required to identify inhibitors of oxidative phosphorylation, which are more potent than MET.

\section{Acknowledgements}

The present study was supported by the Natural Science Foundation of Jiangsu Province (grant no. BK20131157).

\section{References}

1. Siegel RL, Miller KD and Jemal A: Cancer statistics, 2015. CA Cancer J Clin 65: 5-29, 2015.

2. Xu Q, Zhang TP and Zhao YP: Advances in early diagnosis and therapy of pancreatic cancer. Hepatobiliary Pancreat Dis Int 10: 128-135, 2011

3. Stathis A and Moore MJ: Advanced pancreatic carcinoma: Current treatment and future challenges. Nat Rev Clin Oncol 7: 163-172, 2010. 
4. Burris HR, Moore MJ, Andersen J, Green MR, Rothenberg ML, Modiano MR, Cripps MC, Portenoy RK, Storniolo AM, Tarassoff $\mathrm{P}$, et al: Improvements in survival and clinical benefit with gemcitabine as first-line therapy for patients with advanced pancreas cancer: A randomized trial. J Clin Oncol 15: 2403-2413, 1997.

5. He H, Ke R, Lin H, Ying Y, Liu D and Luo Z: Metformin, an old drug, brings a new era to cancer therapy. Cancer J 21: 70-74, 2015.

6. Morales DR and Morris AD: Metformin in cancer treatment and prevention. Annu Rev Med 66: 17-29, 2015.

7. Kisfalvi K, Moro A, Sinnett-Smith J, Eibl G and Rozengurt E: Metformin inhibits the growth of human pancreatic cancer xenografts. Pancreas 42: 781-785, 2013.

8. Bao B, Wang Z, Ali S, Ahmad A, Azmi AS, Sarkar SH, Banerjee S, Kong D, Li Y, Thakur S and Sarkar FH: Metformin inhibits cell proliferation, migration and invasion by attenuating CSC function mediated by deregulating miRNAs in pancreatic cancer cells. Cancer Prev Res (Phila) 5: 355-364, 2012.

9. Wang LW, Li ZS, Zou DW, Jin ZD, Gao J and Xu GM: Metformin induces apoptosis of pancreatic cancer cells. World J Gastroenterol 14: 7192-7198, 2008.

10. Gao ZY, Liu Z, Bi MH, Zhang JJ, Han ZQ, Han X, Wang HY, Sun GP and Liu H: Metformin induces apoptosis via a mitochondria-mediated pathway in human breast cancer cells in vitro. Exp Ther Med 11: 1700-1706, 2016.

11. Fujimori T, Kato K, Fujihara S, Iwama H, Yamashita T, Kobayashi K, Kamada H, Morishita A, Kobara H, Mori H, et al: Antitumor effect of metformin on cholangiocarcinoma: In vitro and in vivo studies. Oncol Rep 34: 2987-2996, 2015.

12. Ramjeesingh R, Orr C, Bricks CS, Hopman WM and Hammad N: A retrospective study on the role of diabetes and metformin in colorectal cancer disease survival. Curr Oncol 23: e116-e122, 2016.

13. Owen MR, Doran E and Halestrap AP: Evidence that metformin exerts its anti-diabetic effects through inhibition of complex 1 of the mitochondrial respiratory chain. Biochem J 348: 607-614, 2000.

14. El-Mir MY, Nogueira V, Fontaine E, Averet N, Rigoulet M and Leverve X: Dimetforminhylbiguanide inhibits cell respiration via an indirect effect targeted on the respiratory chain complex I J Biol Chem 275: 223-228, 2000.

15. Gallagher EJ and LeRoith D: Minireview: IGF, insulin, and cancer. Endoscopy 152: 2546-2255, 2011.

16. Algire C, Moiseeva O, Deschênes-Simard X, Amrein L, Petruccelli L, Birman E, Viollet B, Ferbeyre G and Pollak MN: Metformin reduces endogenous reactive oxygen species and associated DNA damage. Cancer Prev Res (Phila) 5: 536-543, 2012.

17. Hirsch HA, Iliopoulos D and Struhl K: Metformin inhibits the inflammatory response associated with cellular transformation and cancer stem cell growth. Proc Natl Acad Sci USA 110: 972-977, 2013

18. Gou S, Cui P, Li X, Shi P, Liu T and Wang C: Low concentrations of metformin selectively inhibit CD133 (+) cell proliferation in pancreatic cancer and have anticancer action. Plos One 8: e63969, 2013.

19. Breckenridge DG and Xue D: Regulation of mitochondrial membrane permeabilization by BCL-2 family proteins and caspases. Curr Opin Cell Biol 16: 647-652, 2004.
20. Yang J, Liu X, Bhalla K, Kim CN, Ibrado AM, Cai J, Peng TI, Jones DP and Wang X: Prevention of apoptosis by Bcl-2: Release of cytochrome c from mitochondria blocked. Science 275: 1129-1132, 1997

21. Amundson SA, Myers TG, Scudiero D, Kitada S, Reed JC and Fornace AJ Jr: An informatics approach identifying markers of chemosensitivity in human cancer cell lines. Cancer Res 60: 6101-6610, 2000.

22. Mobahat M, Narendran A and Riabowol K: Survivin as a preferential target for cancer therapy. Int J Mol Sci 15: 2494-2516, 2014.

23. Hassan M, Watari H, AbuAlmaaty A, Ohba Y and Sakuragi N: Apoptosis and molecular targeting therapy in cancer. Biomed Res Int 2014: 150845, 2014

24. Kim JK and Diehl JA: Nuclear cyclin D1: An oncogenic driver in human cancer. J Cell Physiol 220: 292-296, 2009.

25. Juríková M, Danihel L, Polák Š and Varga I: Ki67, PCNA, and MCM proteins: Markers of proliferation in the diagnosis of breast cancer. Acta Histochem: 30084-30088, 2016 (Epub ahead of print).

26. Vincent A, Herman J, Schulick R, Hruban RH and Goggins M: Pancreatic cancer. Lancet 378: 607-620, 2011.

27. Colucci G, Labianca R, Di Costanzo F, Gebbia V, Cartenì G, Massidda B, Dapretto E, Manzione L, Piazza E, Sannicolò $\mathrm{M}$, et al: Randomized phase III trial of gemcitabine plus cisplatin compared with single-agent gemcitabine as first-line treatment of patients with advanced pancreatic cancer: The GIP-1 study. J Clin Oncol 28: 1645-1651, 2010.

28. Abou-Alfa GK, Letourneau R, Harker G, Modiano M, Hurwitz H, Tchekmedyian NS, Feit K, Ackerman J, De Jager RL, Eckhardt SG and O'Reilly EM: Randomized phase III study of exatecan and gemcitabine compared with gemcitabine alone in untreated advanced pancreatic cancer. J Clin Oncol 24: 4441-4447, 2006

29. Cunningham D, Chau I, Stocken DD, Valle JW, Smith D, Steward W, Harper PG, Dunn J, Tudur-Smith C, West J, et al: Phase III randomized comparison of gemcitabine versus gemcitabine plus capecitabine in patients with advanced pancreatic cancer. J Clin Oncol 27: 5513-5518, 2009.

30. Gong J, Robbins LA, Lugea A, Waldron RT, Jeon CY and Pandol SJ: Diabetes, pancreatic cancer, and metformin therapy. Front Physiol 5: 426, 2014.

31. Choi Y, Kim TY, Oh DY, Lee KH, Han SW, Im SA, Kim TY and Bang YJ: The impact of diabetes mellitus and metformin treatment on survival of patients with advanced pancreatic cancer undergoing chemotherapy. Cancer Res Treat 48: 171-179, 2016.

32. Sadeghi N, Abbruzzese JL, Yeung SC, Hassan M and Li D: Metformin use is associated with better survival of diabetic patients with pancreatic cancer. Clin Cancer Res 18: 2905-2912, 2012.

33. Zhang JW and Sun Q: Metformin may improve the prognosis of patients with pancreatic cancer. Asian Pac J Cancer Prev 16: 3937-3940, 2015.

34. Kordes S, Pollak MN, Zwinderman AH, Mathôt RA, Weterman MJ, Beeker A, Punt CJ, Richel DJ and Wilmink JW: Metformin in patients with advanced pancreatic cancer: A double-blind, randomised, placebo-controlled phase 2 trial. Lancet Oncol 16: 839-847, 2015. 